\title{
Adaptações Morfoanatômicas de Cyperaceae ao Ambiente AQUÁTICO ${ }^{1}$
}

\author{
Morphology and Anatomic Adaptations of Cyperaceae Aquatic Habits \\ ROCHA, D.C. ${ }^{2}$ e MARTINS, D. ${ }^{3}$
}

\begin{abstract}
RESUMO - No ecossistema aquático há uma faixa de umidade gradiente no solo que interfere diretamente na ocupação das espécies à margem da lâmina de água. Essa zonação ecológica reflete os graus de adaptação que as plantas apresentam para tolerar o alagamento ou a dessecação. O presente trabalho visou apresentar a análise morfoanatômica de cinco espécies de Cyperaceae encontradas em diferentes zonas no entorno da represa Alagados, em Ponta Grossa-PR, Brasil: Cyperus giganteus, Rhynchospora corymbosa var. aspérula, Cyperus densicaespitosus, Cyperus rigens e Eleocharis sp. Estruturas caulinares e foliares das cinco espécies de Cyperaceae foram analisadas a partir de cortes histológicos. Concluiu-se que, das cinco plantas analisadas, somente três caracterizam-se como plantas aquáticas, sendo duas classificadas como plantas emergentes e uma como submersa fixa devido às caracteristicas adaptativas que apresentam para obter sucesso nesse ambiente.
\end{abstract}

Palavras-chave: anatomia caulinar, anatomia foliar, aerênquima, estresse.

ABSTRACT - In the aquatic ecosystem there is gradient moisture in the soil that interferes directly in the occupation of species on the margin of the water blade. This ecological zone reflects the degrees of adaptation that plants present to tolerate flooding or drying. This work aimed to present a morphological and anatomical analysis of five species of Cyperaceae, found at different zones in the surroundings of the Alagados Dam, in Ponta Grossa-PR, Brazil: Cyperus giganteus and Rhynchospora corymbosa var. asperula, Cyperus densicaespitosus, Cyperus rigens and Eleocharis sp. Stem and foliar structures of five species of Cyperaceae were analyzed by histological cross-section. It was concluded that of the five plants examined, only three are aquatic plants, with two being classified as emerging plants and one as fixed submerged, based on the adaptive characteristics they present to succeed in this environment.

Keywords: stem anatomy, foliar anatomy, aerenchyma, stress

\section{INTRODUÇÃO}

A familia Cyperaceae Juss. é cosmopolita e de hábito herbáceo, cujos representantes crescem, na sua maioria, em regiões alagadas ou sujeitas a inundações, mas também podem ocorrer em locais secos (Dalhgren et al., 1985; Bove et al., 2003; Gil \& Bove, 2004, 2007).

A presença de plantas em ambientes aquáticos continentais é fundamental para o equilíbrio desses ecossistemas, tanto naturais, como lagos, rios e riachos, quanto artificiais, como reservatórios de hidrelétricas, represas e açudes para abastecimento de água. Entretanto, tem sido cada vez mais necessário o monitoramento das espécies que ocorrem nesses ambientes, uma vez que estes sofrem constantes pressões antrópicas e se alteram.

Nas últimas duas décadas, os casos de desequilíbrio populacional estão aumentando, principalmente em lagos artificiais que servem como reservatórios de abastecimento de água ou de usinas hidrelétricas. Esse desequilíbrio gera crescimento acelerado de

1 Recebido para publicação em 14.1.2011 e na forma revisada em 18.2.2011.

2 Profa. Adj., Dep. de Biologia Geral, Universidade Estadual de Ponta Grossa - UEPG, 84030-900 Ponta Grossa-PR, <rocha.dalva@hotmail.com>; ${ }^{3}$ Professor Livre Docente, Dep. de Produção Vegetal, Faculdade de Ciências Agronômicas FCA/UNESP, Caixa Postal 237, 18603-970 Botucatu-SP, <dmartins@fca.unesp.br>. 
ROCHA, D.C. \& MARTINS, D.

uma população de plantas em detrimento de outras, devido ao processo de eutrofização do ambiente provocado pelos dejetos de resíduos urbanos industriais e/ou residenciais, bem como de resíduos rurais lançados na água (Pinto \& Cavalcanti, 2001; Tanaka et al., 2002; Thomaz, 2002; Cavenaghi et al., 2003). Nesses casos, torna-se necessário tomar medidas de controle do crescimento populacional em desequilíbrio das plantas; para isso, estudos sobre a biologia dessas plantas devem ser enfatizados.

No ecossistema aquático existe uma faixa de umidade gradiente no solo, que interfere diretamente na ocupação das espécies à margem da lâmina de água. Segundo ScremimDias (2000), essa zonação ecológica reflete os graus de adaptação que as plantas apresentam para tolerar o alagamento ou a dessecação, colonizando assim desde as áreas marginais até o interior do corpo de água.

Irgang et al. (1984) utilizaram uma terminologia para classificar as plantas aquáticas com base no nível de inundação que elas suportam. Segundo esses autores, plantas flutuantes fixas (FF) são enraizadas no fundo do lago, com folhas flutuantes na lâmina da água; flutuantes livres (FL) não se fixam aos substratos e permanecem livres na lâmina de água; submersas fixas (SF) são enraizadas no fundo do lago e mantêm o corpo vegetativo completamente submerso; submersas livres (SF) são aquelas cujas raízes são pouco desenvolvidas, podendo se prender a caules e pecíolos de outras plantas aquáticas; anfibias (AF) são aquelas que vivem à margem de corpos d'água, permanecendo dentro da água apenas durante o periodo de inundação, mas que sobrevivem por períodos variáveis no solo livre de inundação; emergentes são plantas que vivem dentro da água, porém com as folhas crescendo fora dele; e epífitas, quando se apresentam sobre plantas aquáticas.

Com base nessa classificação, entende-se que plantas flutuantes e submersas são menos tolerantes ao dessecamento que plantas emergentes ou anfibias e que, para ocuparem esse habitat, apresentam adaptações morfológicas e anatômicas indicadoras.

O objetivo deste trabalho foi apresentar aspectos morfoanatômicos de cinco representantes da família Cyperaceae que ocupam áreas alagadas no entorno da represa Alagados, em Ponta Grossa-PR, Brasil.

\section{MATERIAL E MÉTODOS}

Cinco espécies de Cyperaceae foram coletadas no entorno da represa Alagados, em Ponta Grossa-PR. Essa represa gera energia elétrica e abastece parcialmente a cidade de Ponta Grossa. É formada por um lago artificial, que também é utilizado para lazer da população regional, a qual mantém residências e um Iate Club às suas margens, além de fazer divisa com muitas propriedades rurais, que desenvolvem atividades de lavoura e suinocultura (Pilatti, 2002).

Cyperus giganteus e Rhynchospora var. asperula ocupam áreas marginais do lago, alagáveis apenas quando o volume de água armazenada eleva-se demasiadamente. Três outras espécies, Cyperus densicaespitosus, Cyperus rigens e Eleocharis sp., foram coletadas em áreas marginais que sofrem frequente alagamento e, por isso, podem permanecer totalmente submersas por longo período no ano. As exsicatas dessas cinco espécies constam do acervo do Herbário da Universidade Estadual de Ponta Grossa, HUPG, indexado no Taxon Online e no Index Herbariorum.

Caules e folhas das plantas foram fixados em FAA 70 e, posteriormente, armazenados em álcool $70 \%$, para os procedimentos usuais de microtécnica vegetal. Para o preparo de lâminas histológicas semipermanentes, o material foi seccionado a mão livre e corado com azul de toluidina, ou foi submetido à dupla coloração com azul de metileno e fuccina básica (Kraus \& Arduim, 1997).

As fotomicrografias dos tecidos foram realizadas em microscópio Olympus acoplado a máquina fotográfica. A escala micrométrica foi fotografada nas mesmas condições que os cortes, para comparações.

\section{RESULTADOS E DISCUSSÃO}

\section{Morfoanatomia do escapo}

C. densicaepitosus, C. rigens e Eleochari sp. (Figura 1A, B, e E) são plantas de pequeno porte. Com a elevação do nível das águas, elas 

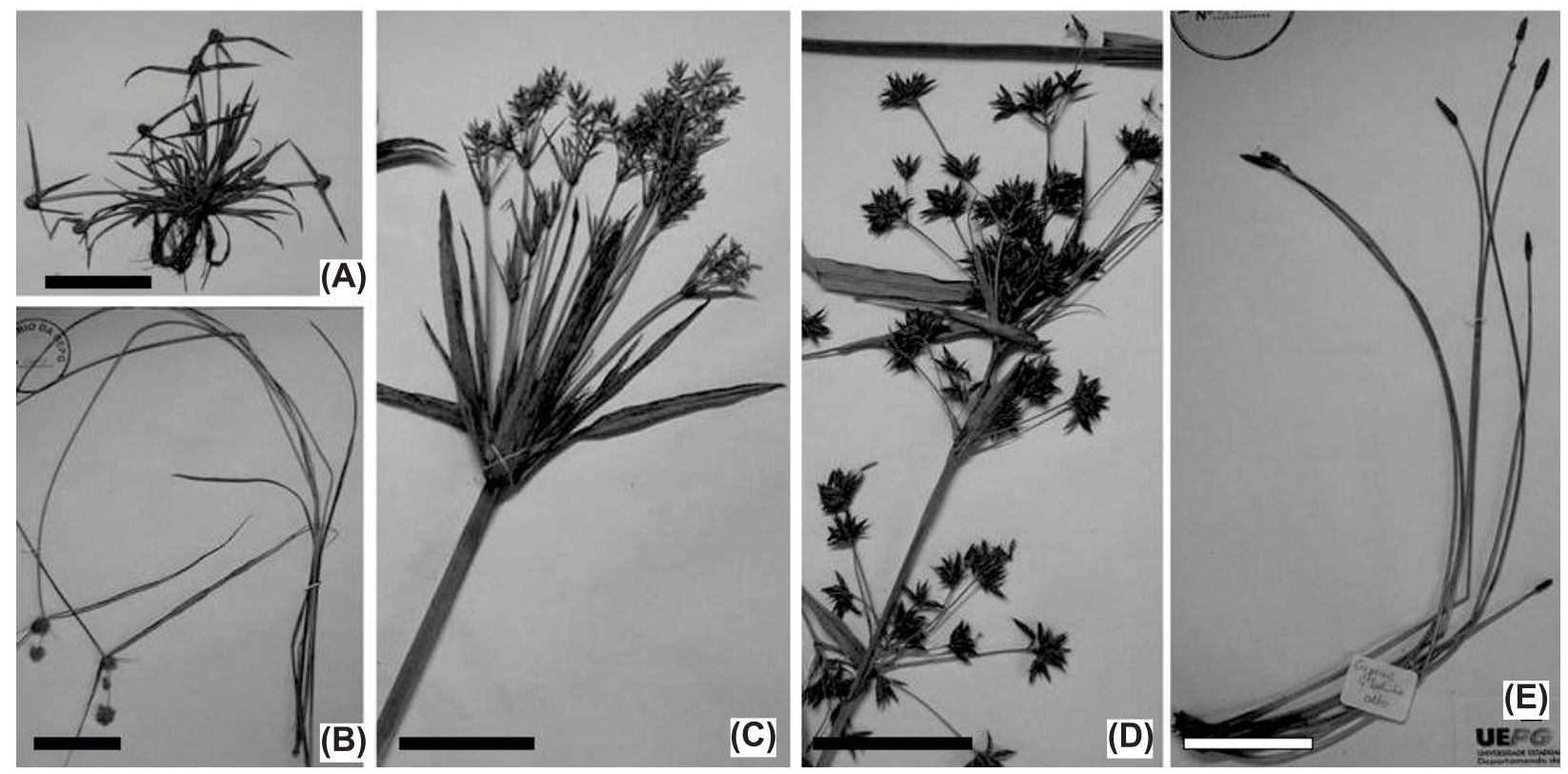

Figura 1 - Aspecto geral de Cyperaceae. (A) Cyperus densicaespitosus.

(D) Rhynchospora corymbosa. (E) Eleocharis sp. Barra $=5 \mathrm{~cm}$.

podem ficar totalmente submersas. As outras duas espécies, C. giganteus e R. corymbosa (Figura 1C e D), são de maior porte e ocupam áreas distantes do filme d'água, o suficiente para nunca ficarem totalmente submersas, o que lhes permite ficar em solo encharcado e/ ou parcialmente submersas durante apenas um curto período de chuvas (inverno), enfrentando o dessecamento durante toda a estação seca (verão).

A estrutura caulinar em Cyperaceae limita-se ao escapo da inflorescência de todas as espécies estudadas, uma vez que não foram observados outros órgãos aéreos com essas características, corroborando os dados de Estelita $\&$ Rodrigues (2007) e Prata et al. (2007).

Na Figura 2 estão apresentadas as características anatômicas do escapo das cinco espécies. Nota-se que o formato tipicamente triangular do escapo, atribuído frequentemente às Cyperaceae para diferenciá-las de Poaceae, não ocorre em todas as espécies e também não parece caracterizar gêneros em Cyperaceae, pois, das cinco espécies analisadas, somente três delas apresentaram essa característica, sendo duas do gênero Cyperus e uma de Rhynchospora. Em C. giganteus, o contorno da seção transversal do escapo é circular nas porções mais basais (Figura 2A), e o mesmo é observado em todas as porções do escapo de Eleocharis sp. (Figura 2E).

Essa variação do formato da secção transversal do escapo, triangular ou circular, não é uma característica exclusiva de Cyperaceae, pois Coan et al. (2002) observaram também em espécies aquáticas de Eriocaulaceae.

Estômatos foram observados na epiderme caulinar de todas as espécies, assim como também foi notada semelhante organização interna dos tecidos em duas regiões que podem caracterizar-se como córtex e medula, com a concentração do tecido clorofilado e feixes vasculares no córtex (Figura 2).

Observa-se que há aerênquima intercalado com parênquima clorofiliano na região cortical do escapo em $R$. corymbosa (Figura 2B e 3B) e que o córtex é compacto nas demais espécies. Por outro lado, foi constatado aerênquima regular com células braciformes na região da medula no escapo de $C$. giganteus (Figura 3A). Na região medular do escapo de C. densicaepitosus e de C. rigens foram observadas poucas e pequenas lacunas de formato irregular (Figura 3C e D), e na região central do escapo em Eleocharis sp. foi possivel notar 


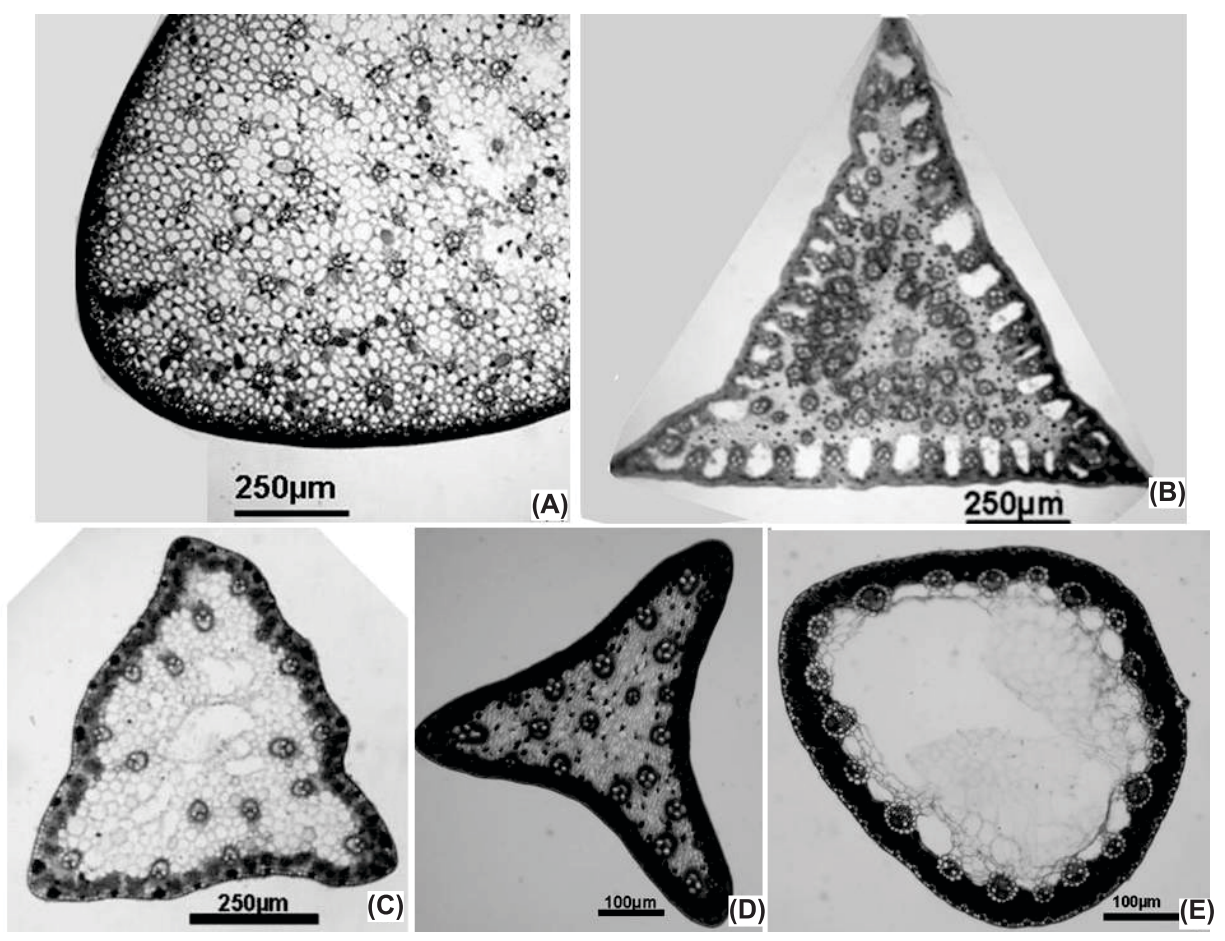

Figura 2 - Secção transversal da estrutura caulinar de Cyperaceae. (A) Cyperus giganteus. (B) Rhynchospora corymbosa.(C) Cyperus densicaepitosus. (D) Cyperus rigens. (E) Eleocharis sp.

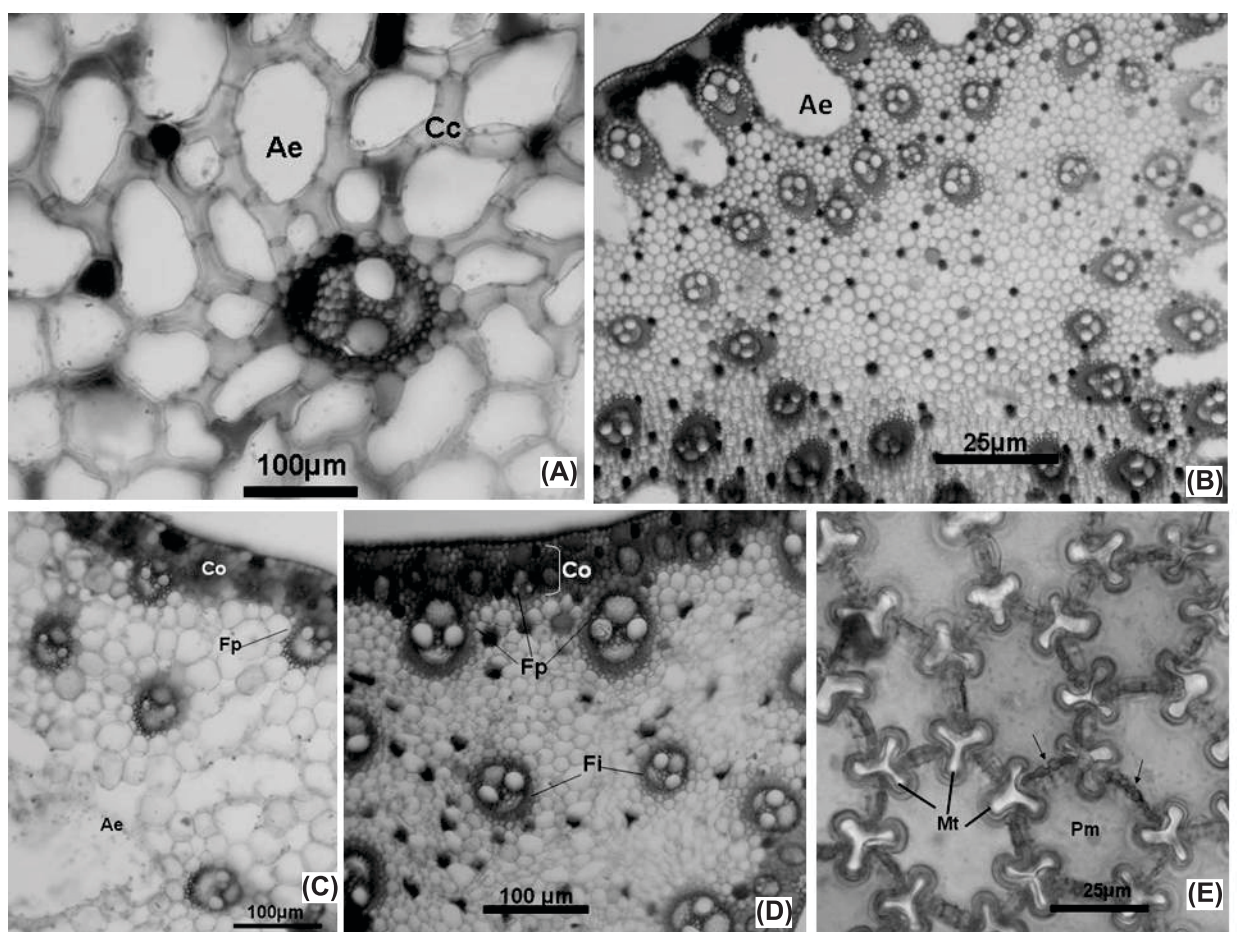

Figura 3 - Detalhes da região medular do escapo e Cyperaceae. A. Cyperus giganteus. B. Rhynchospora corymbosa. C. Cyperus densicaepitosus. D. Cyperus rigens. E. Eleocharis sp. Ae = aerênquima; $\mathrm{Cc}=$ células braciformes; $\mathrm{Co}=$ córtex; Fi = feixe interno; $\mathrm{Fp}=$ feixe periférico; $\mathrm{Mt}=$ meatos; $\mathrm{Pm}=$ parênquima medular. 
meatos, ou seja, pequenos espaços intercelulares com aparência trifurcada (Figura 3E).

Fahn (1982) menciona que o aerênquima com células estreladas é comum em plantas aquáticas que não permanecem submersas e cita Cyperus distachyos como exemplo.

A presença de aerênquima bem desenvolvido é característica de plantas aquáticas (Bona \& Morretes, 2003). Entretanto, as plantas não adaptadas ao ambiente aquático e submetidas à deficiência de oxigênio ou de nutrientes produzem lacunas entre as células parenquimáticas como resposta anatômica $\mathrm{e}$ fisiológica decorrente do aumento na atividade da celulase, que por sua vez é favorecida pela maior produção de etileno endógeno em condições de estresse (Kawase \& Whitmoyer, 1980; Drew et al., 1989; Bouranis et al., 2006; Pereira et al., 2008). Elas se formam por lise celular; portanto, são irregulares no formato e na frequência.

As lacunas de formato regular no escapo de $C$. giganteus, $R$. corymbosa e Eleocharis sp. parecem ser formadas esquizogenamente, enquanto as lacunas irregulares formadas no escapo de $C$. densicaepitosus e $C$. rigens aparentam ter origem lisigena.

Quanto à disposição do sistema vascular, notou-se que existe concentração de pequenos feixes vasculares próximo à epiderme, formando o córtex no escapo de todas as espécies estudadas. Entretanto, nas três espécies de Cyperus e de Rhynchospora também há feixes vasculares na região central do escapo, ou seja, na medula, onde estes são maiores que os do córtex. Observa-se mais claramente o arranjo radiado do parênquima, envolvendo total ou parcialmente os feixes do córtex nas três espécies de Cyperus (Figura 3A, C e D). Na região central do escapo de Eleocharis sp. não foram observados feixes vasculares, apenas parênquima (Figura 3E).

A presença de parênquima ao redor do feixe vascular é indicada como anatomia kranz e revela o metabolismo $\mathrm{C}_{4}$ da espécie. Muitas ciperáceas possuem bainha kranz, como já foi verificado para os gêneros Cyperus, Eleocharis, Rhynchospora, Fimbristylis e Remirea (Estelita-Teixeira \& Handro, 1987; Estelita, 1993).

\section{Morfoanatomia da folha}

A secção transversal das folhas das cinco plantas estudadas revelou quatro diferentes formatos: folha de C. giganteus apresentou, em secção transversal, a forma de $\mathrm{W}$; as folhas de $R$. corymbosa e de $C$. densicaepitosus, o formato de V; a folha de C. rigens, o formato de V; e a folha de Eleocharis sp. apresenta-se como semicircular (Figura 4).

Os variados formatos das folhas de Cyperaceae em corte transversal foram notificados por Metcalfe (1969), que interpretou essa variação como o reflexo de três possivieis linhas de evolução para a formação dos três tipos de organização estrutural: dorsiventral, pseudodorsiventral e isobilateral. Esse autor ressalta que o formato cilindrico da folha de Cyperaceae tem estrutura pseudodorsiventral, que pode ter sido formada pelo entumescimento do limbo e soldadura das margens de folhas com estrutura dorsiventral. Contudo, possivelmente algumas folhas com estrutura dorsiventral que não sofreram entumescimento, mas que desenvolveram a curvatura gradativa das margens, deram origem às folhas com estrutura isobilateral.

Os formatos em $\mathrm{W}$ e em $\mathrm{V}$ podem ser aqui considerados variações do formato em $\mathrm{V}$, pois todos apresentam a orientação dos tecidos da estrutura dorsiventral, com xilema adaxial e floema abaxial, conforme descrito por Metcalfe (1969).

Foi constatado que a folha de Eleocharis sp. (Figura 4I-J) tem a aparência de bainha, porém também apresenta a estrutura dorsiventral. A análise anatômica revelou também o mesofilo contendo duas camadas de parênquima paliçádico próximo à epiderme adaxial, com feixes vasculares intercalados por regiões de aerênquima e duas a três camadas de parênquima de preenchimento voltado para a região abaxial. Não foi possível identificar a camada da epiderme abaxial (Figura 4I-J).

De acordo com Gil \& Bove (2007), a análise morfológica do gênero Eleocharis dificulta a percepção da lâmina foliar, e a consequência disso é o relato de ausência de folhas para esse táxon. Em descrições do gênero, considera-se que a planta tenha apenas bainha. 


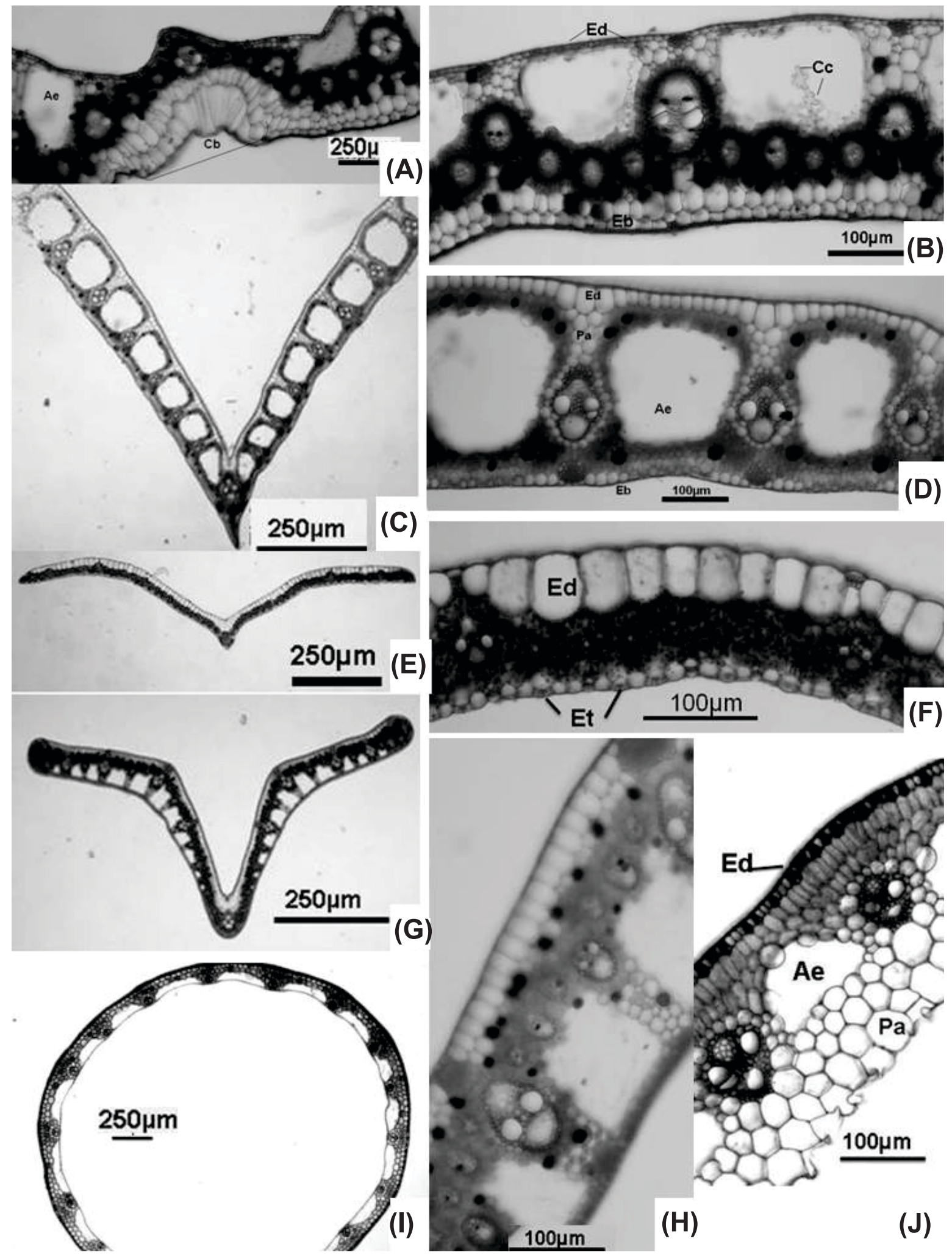

Figura 4 - Anatomia foliar de Cyperaceae. (A-B) Cyperus giganteus. (C-D) Rhynchospora corymbosa. (E-F) Cyperus densicaepitosus. (G-H) Cyperus rigens. (I-J) Eleocharis $\mathrm{sp}$. Ae = aerênquima; $\mathrm{Cb}=$ células buliformes; $\mathrm{Cc}=$ células braciformes; $\mathrm{Eb}=$ face abaxial da epiderme; $\mathrm{Ed}=$ face adaxial da epiderme; $\mathrm{Et}=$ estômato; $\mathrm{Fv}=$ feixe interno; $\mathrm{Pa}=$ parênquima. 
No presente trabalho, a análise anatômica das seções transversais constatou serem anfiestomáticas as folhas de $C$. giganteus (Figura 4A, B), de R. corymbosa (Figura 4C-D), de $C$. densicaepitosus (Figura 4E-F) e de C. rigens (Figura $4 \mathrm{G}-\mathrm{H}$ ), com mais estômatos na face abaxial. Na folha dessas espécies também se pode identificar a região da nervura central, onde um feixe vascular maior se desenvolve e onde há células buliformes. Verificou-se que em $C$. giganteus elas estão na face abaxial (Figura 4A), e nas demais espécies elas são observadas na face adaxial da epiderme. Não foram observadas células buliformes na folha de Eleocharis sp. (Figura J).

A presença de hipoderme foi constatada apenas em duas das três espécies de Cyperus analisadas. Não foi verificada hipoderme em C. densicaepitosus (Figuras 4D-E), R. corymbosa (Figura 4B-C) e Eleocharis sp. (Figuras I-J).

No mesofilo das folhas de C. giganteus, de $R$. corymbosa, de C. rigens e de Eleocharis sp. foi possivel observar aerênquima intercalado com parênquima clorofiliano ao redor dos feixes (Figura 4B, D, H, J), mas nas folhas de $C$. densicaepitosus o mesofilo pode ser considerado compacto, ou seja, os tecidos se organizam sem formar espaços intercelulares significativos que possam configurar lacunas de aerênquima (Figura 4F).

Observando o sistema vascular, notou-se o arranjo radiado do parênquima clorofiliano envolvendo total ou parcialmente o feixe vascular das folhas, nas três espécies de Cyperus e nos feixes vasculares das folhas de $R$. corymbosa; em Eleocharis sp. notou-se a presença de endocerme e periciclo (Figura 4B, $\mathrm{D}, \mathrm{F}, \mathrm{H}, \mathrm{J})$.

A presença de bainha ao redor do feixe vascular e indicada como anatomia kranz geralmente revela o metabolismo $\mathrm{C}_{4}$ da espécie. Muitas ciperáceas possuem bainha kranz, como já foi verificado para os gêneros Cyperus, Eleocharis, Rhynchospora, Fimbristylis e Remirea (Estelita-Teixeira \& Handro, 1987; Estelita, 1993). Segundo Takeda et al. (1985), em Cyperaceae há quatro tipos distintos de anatomia foliar $\mathrm{C}_{4}$ ("clorocyperoide, fimbristyloide, eleocharoide e rhynchosporoide"), que diferem na posição do periciclo (denominado pelos autores de Photosynthetic
Carbon Reduction - PCR), presença ou ausência de endoderme (denominada bainha vascular parenquimática) e pela posição dos elementos de vaso do metaxilema em relação ao PCR.

Metcalfe (1971) considerou a presença de hipoderme e de parênquima radiado envolvendo feixes vasculares, bem como a distinção de parênquima paliçádico e lacunoso no mesofilo, como sendo caracteres com valor taxonômico para Cyperaceae. Contudo, no presente trabalho não foi possivel fazer considerações aprofundadas sobre aspectos anatômicos com valor taxonômico, visto que foram analisadas somente três espécies do gênero Cyperus, uma de Rhynchospora e uma de Eleocharis. Por outro lado, é possivel fazer considerações sobre aspectos anatômicos adaptativos.

\section{Adaptações ao ambiente aquático}

Segundo Fahn (1982), as características adaptativas para o ambiente aquático, especialmente para plantas submersas, são: tecido clorofiliano desenvolvido inclusive em caules, aerênquima, cutícula fina, tecido de armazenamento (lipídios ou amido), abundância de tecidos com células de parede delgada e sistema vascular menos desenvolvido e com pouco xilema.

A presença do aerênquima é a adaptação mais frequente para o ambiente aquático observada nessas cinco espécies de ciperáceas avaliadas no presente trabalho. Considerando que sob estresse de alagamento as lacunas se formam por ruptura das células, enquanto lacunas esquizógenas são comuns em plantas aquáticas não submersas, pode-se inferir que C. densicaepitosus e C. rigens não são plantas aquáticas adaptadas, apesar de terem sido encontradas nesse ambiente e de a presença de lacunas irregulares ser fator indicativo de que estão respondendo ao estresse do alagamento. Além disso, a disposição dos estômatos com predominância na face abaxial da epiderme e a presença de células buliformes também demonstram que essas espécies não são adaptadas a viver submersas.

$\mathrm{Na}$ folha de $C$. rigens observa-se ainda considerável proporção de tecido esclerificado - outra característica que também sustenta a hipótese de que essa espécie não está adaptada ao ambiente aquático. 
Por outro lado, C. giganteus e $R$. corymbosa possuem aerênquima esquizógeno, tanto no caule como na folha, com estomatos em ambas as faces da epiderme foliar e com células buliformes na região da nervura central da folha, todas caracteristicas para enfrentar períodos de dessecação, sustentando a hipótese de ocupação como plantas emergentes, adaptadas às condições de inundação parcial dos órgãos em um período e de estresse de dessecação em outro.

No caso de Eleocharis sp., que também foi coletada muito próximo à margem do lago, em área normalmente alagada, notou-se um conjunto de características que sustentam sua classificação como submersa: duas camadas de parênquima paliçádico no mesofilo da folha envolta no escapo, estômatos presentes somente na face adaxial da epiderme e ausência de células buliformes. Essa espécie tem ainda aerênquima com lacunas regulares, aparentemente esquizógeno, que indica seu maior grau de adaptação à inundação.

Nas várias descrições de espécies de Eleocharis (2007) menciona-se a ocorrência em locais úmidos e alagáveis, indicando que esse hábito é comum no gênero.

Conclui-se que apenas três das cinco espécies estudadas são plantas aquáticas: C. giganteus, $R$. corymbosa e Eleocharis sp. As duas primeiras são classificadas como plantas emergentes, e a última, como submersa fixa, pelas características adaptativas que apresentam para obter sucesso nesse ambiente.

\section{LITERATURA CITADA}

BONA, C.; MORRETES, B. L. Anatomia das raízes de Bacopa salzmanii (Benth.) Wettst. ex Edwall e Bacopa monnierioides (Cham.) Robinson (Scrophulariaceae) em ambientes aquático e terrestre. Acta Bot. Bras., v. 17, n. 1, p. 155-170, 2003.

BOVE, C. P. et al. Hidrófitas fanerogâmicas de ecossistemas aquáticos temporários da planície costeira do Estado do Rio de Janeiro, Brasil. Acta Bot. Bras., v. 17, n. 1, p. 119-135, 2003.

BOURANIS, D. L. et al. Dynamics of Aerenchyma distribution in the cortex of sulfate-deprived adventitious roots of maize. Ann. Bot., v. 97, n. 5, p. 695-704, 2006.

Planta Daninha, Viçosa-MG, v. 29, n. 1, p. 7-15, 2011
CAVENAGHI, A. L. et. al. Caracterização da qualidade de água e sedimento relacionados com a ocorrência de plantas aquáticas em cinco reservatórios da Bacia do Rio Tietê.

Planta Daninha, v. 21, p. 43-52, 2003. (Edição Especial)

COAN, A. I.; SCATENA, V. L.; GIULIETTI, A. M.

Anatomia de algumas espécies aquáticas de Eriocaulaceae brasileiras. Acta Bot. Bras., v. 16, n. 4, p. 371-384, 2002.

DAHLGREN, R. M. T.; CLIFFORD, H. T.; YEO, P. F. The familie of the monocotyledons:structure, evolution and taxonomy. Berlin: Springer-Verlag, 1985. 242 p.

DREW, M. C.; HE, C. J.; MORGAN, P. W. Decreased ethylene biosynthesis, and induction of aerenchyma, by nitrogen- or phosphate-starvation in adventitious roots of Zea mays L.. Plant Physiol., v. 91, n. 2, p. 266-271, 1989.

ESTELITA, M. E. M. Anatomia dos órgãos vegetativos de Remeria maritima Aubl. (Cyperaceae). Naturalia, v. 18, p. 123-134, 1993.

ESTELITA-TEIXEIRA, M. E. M.; HANDRO, W. Kranz pattern in leaf, scape and bract of Cyperus and Fimbristylis species. R. Bras. Bot., v. 10, n. 1, p. 105-111, 1987.

ESTELITA, M. E. M.; RODRIGUES, A. C. Subsídios estruturais à caracterização do sistema caulinar em Cyperaceae. R. Bras. Bot., v. 30, n. 3, p. 401-409, 2007.

FAHN, A. Plant anatomy. São Paulo: Pergamon Press, 1982. $356 \mathrm{p}$.

GL, A. S. B.; BOVE, C. P. O gênero Eleocharis R. Br. (Cyperaceae) nos ecossistemas aquáticos temporários da planície costeira do Estado do Rio de Janeiro. Arq. Mus. Nac., v. 62, n. 2, p. 131-150, 2004.

GIL, A. S. B.; BOVE, C. P. Eleocharis R. Br. (Cyperaceae) no Estado do Rio de Janeiro, Brasil. Biota Neotrop., v. 7, n. 1, p. $36-45,2007$.

IRGANG, B. E.; PEDRALLI, G.; WAECHTER, J. L. Macrófitos aquáticos da estação Ecologia do Taim, Rio Grande do Sul, Brasil. Rosseleria, v. 6, p. 395-404, 1984.

KAWASE, M.; WHITMOYRE, R. E. Aerenchyma development in waterlogged plants. Am. J. Bot., v. 67, v. 1, p. $18-22,1980$

KRAUS, J. E.; ARDUIM, M. Manual básico de métodos em morfologia vegetal. Seropédica: EDUR, 1997. 158 p.

METCALFE, C. R. Anatomy as an aid to classifying the Cyperaceae. Am. J. Bot., v. 56, n. 7, p. 782-790, 1969. 
METCALFE, C. R. Anatomy of the monocotyledons. Cyperaceae. Oxford: Oxford University Press, 1971. v. 5. $239 \mathrm{p}$.

PEREIRA, F. J. et. al. Evolução da anatomia radicular do milho 'Saracura' em ciclos de seleção sucessivos. Pesq. Agropec. Bras., v. 43, n. 12, p. 1649-1656, 2008.

PILATTI, F. (Coord.) Bacia hidrográfica do manancial Alagados. Ponta Grossa: UEPG/COPEL/SANEPAR/ALL/ IAP. 2002. 86 p. (Relatório Técnico)

PINTO, M. A.; CAVALCANTI, C. G. B. Recuperação de lagos tropicais: biotecnologia no controle da eutrofização em lagos tropicais - a experiência do Lago Paranoá. Disponível em: $<$ http://www.biotecnologia.com.br./bio/7 h.htm $>$ Acesso em: 21 jul. de 2008 .

PRATA, A. P. et al. Anatomia do escapo e rizoma de espécies brasileiras de Bulbostylis Kunth (Cyperaceae). R. Bras. Bot., v. 30 , n. 2 , p. $245-256,2007$
SCREMI-DIAS, E. A plasticidade fenotípica das macrófitas aquáticas em resposta à dinâmica ambiental. In: CAVALCANTI, T. B. et al. (Org.) TÓPICOS ATUAIS EM BOTÂNICA. CONGRESSO NACIONAL DE BOTÂNICA, 51., 2000, Brasília. Palestra... Brasília: Embrapa Recursos Genéticos e Biotecnologia-SBB, 2000. p. 187-194.

TAKEDA, T. et al. An investigation of the occurrence of $\mathrm{C}_{4}$ photosynthesis in the Cyperaceae from Australia. Bot. Magaz., v. 98, n. 2, p. 393-411, 1985.

TANAKA, R. H. et al. Ocorrência de plantas aquáticas nos reservatórios da Companhia Energética de São Paulo. Planta Daninha, v. 20, p. 99-111, 2002. (Edição Especial)

THOMAZ, S. M. Fatores ecológicos associados à colonização e ao desenvolvimento de macrófitas aquáticas e desafios de manejo. Planta Daninha, v. 20, p. 21-33, 2002. (Edição Especial) 